\title{
From Ridge to Reef-Linking Erosion and Changing Watersheds to Impacts on the Coral Reef Ecosystems of Hawai'i and the Pacific Ocean
}

\author{
Coral reef ecosystems are \\ threatened by unprecedented \\ watershed changes in the United States \\ and worldwide. These ecosystems \\ sustain fishing and tourism industries \\ essential to the economic survival of \\ many communities. Sediment, nutrients, \\ and pollutants from watersheds are \\ increasingly transported to coastal \\ waters, where these contaminants \\ damage corals. Although pollution \\ from watersheds is one of many \\ factors threatening coral survival, it \\ is one that local people can have a \\ profound influence on. U.S. Geological \\ Survey scientists are using mapping, \\ monitoring, and computer modeling to \\ better forecast the effects of watershed \\ changes on reef health. Working with \\ communities in Hawai'i and on other \\ U.S. islands in the Pacific, they are \\ helping to provide the science needed to \\ make informed decisions on watershed \\ and coral reef management.
}



This image shows the close link between onshore watersheds and nearshore coral reef ecosystems. U.S. Geological Survey scientists are working to understand how watershed and land-use issues are affecting coral reef health in Hawai'i and on other Pacific islands. This scientific information will help policymakers and local communities to make informed land-management decisions. (Image created from USGS photos by Mike Field.)
Coral reef ecosystems are in decline worldwide, and their survival is in doubt in some locations. In response to this ongoing threat, scientists from the U.S. Geological Survey (USGS) are collaborating with local communities and agencies in Hawai ' $i$ and on other U.S. islands in the Pacific Ocean to understand the sources and impacts of sediment, nutrients, and pollutants from watersheds. A watershed is all of the upslope land area that could contribute water and sediment to a stream. Identifying and monitoring effects of landbased contaminants from watersheds on nearshore ecology helps stakeholders evaluate costs and benefits of management actions. Such informed watershed management protects the health of coral reefs, while preserving water and biological resources on land.

The goal of USGS scientists is to quantify watershed changes and their impacts on coral reef ecosystems so that resource managers can make informed decisions. To do this, the USGS is linking measurements of human-induced changes in terrestrial ecosystems with models that estimate erosion. The scientists are using vegetation and surficial mapping, field experiments, sensor networks, and monitoring to create a "sediment budget" for the landscape. By tracking sediment and water movement from upland areas (the "ridge"), down transport paths to coastal

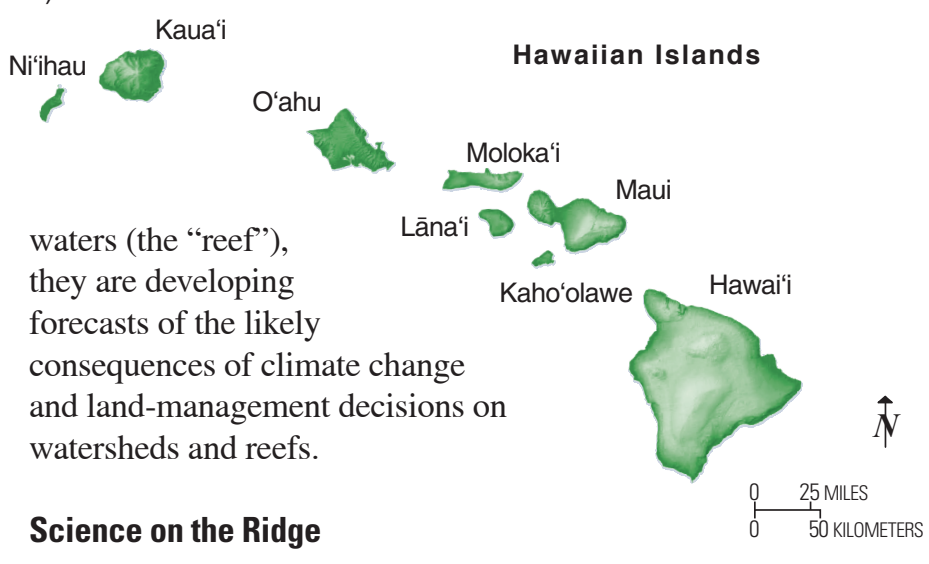

High above the reef, erosion of steep volcanic slopes moves mud and silt into drainage networks. The USGS is quantifying erosion and watershed changes in these steeplands using remote sensing and field data to create very high-resolution geomorphic and vegetation maps. Scientists are combining these maps with measurements of rainfall, infiltration, and the strength of the roots of both native plant communities and invasive species to show how these factors affect changes in soil resistance to landslides and overland flow erosion. They are also 
To better understand how erosion and sediment transport affect the health of coral reefs, the U.S. Geologial Survey has installed instruments in the Kawela watershed on the island of Moloka'i. At this experimental site, scientists are using a rain gage to measure the intensity and duration of rainfall, soil moisture sensors to measure how much water is in the soil, overland flow meters to measure how deep water flow is over the hillslopes, and a flume and pump to measure the amount of water and sediment that run off from the small catchment. When rain falls, the network records data at intervals from 5 seconds to 5 minutes. Erosion rates and susceptibilities measured in detail at such sites can be projected across the rest of the watershed using careful geomorphic mapping. Inset shows a scientist downloading data from an overland flow sensor. (USGS photos by Jonathan Stock and Kevin Schmidt.)

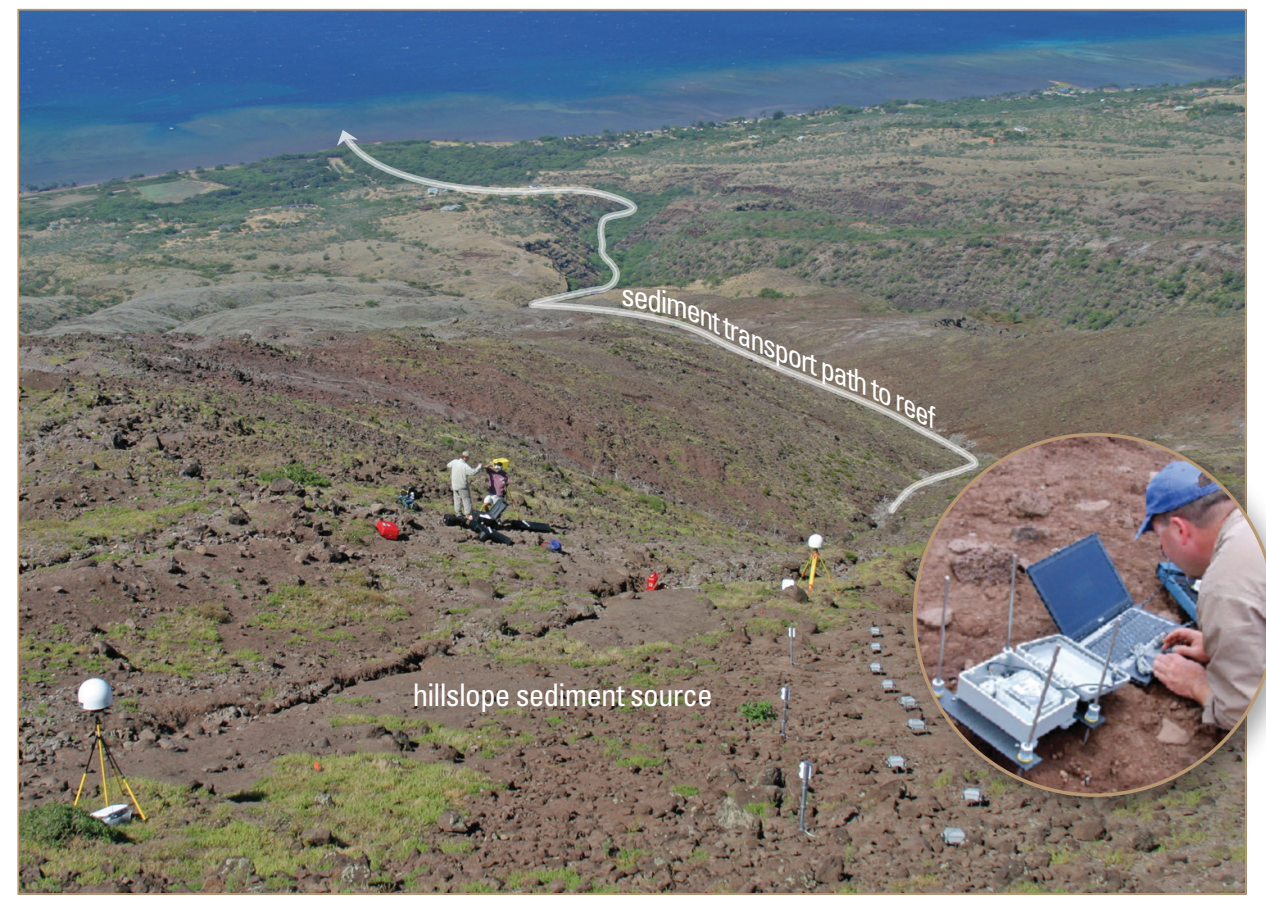

monitoring changes in vegetation composition and structure in response to management actions to restore native-dominated plant communities (for example, efforts to control feral pigs and goats).

To better understand the mechanics of erosion on high islands in the Pacific, USGS scientists have deployed an advanced network of sensors on some of the most severely degraded landscapes on the Hawaiian island of Moloka 'i. During storms, this network measures the intensity and duration of rainfall, the water content of the soil, the depth of water flowing over the hillslope, and the amount of water and sediment runoff. After storms, scientists resurvey the area to detect small changes in topography from erosion using ground-based lidar (light detection and ranging). This highly accurate laser surveying technique can be used to generate centimeter-scale topographic maps for change detection. Scientists are using these maps and sensor readings to quantify erosion rates for hillslopes, the source for fine sediment deposited on nearby reefs. To extend these erosion rates to the whole watershed, they are using satellite and airborne imagery and airborne lidar to create maps of surface processes (for example, rockfall, soil creep, overland flow, and gullying). The scientists are also conducting field experiments to characterize soil infiltration rates and resistance to overland flow erosion, using measurements from infiltrometers and cohesive-strength meters. Radiometric dating methods allow them to estimate longer-term rates of erosion and deposition. By combining mapping, monitoring, and experimental data, USGS researchers are creating sediment budgets to forecast the supply of fine sediment to the reef. In some landscapes, they have found that about $1 \%$ of the watershed area contributes almost half of the annual sediment load.

\section{Science Along the Transport Path}

Mud and silt erode from steep hillslopes during storms and move down toward the reef. To estimate the amount of this fine sediment delivered from eroding uplands to coral reef ecosystems, the USGS has installed stream gages with suspended-sediment collectors on Kaua'i, Moloka 'i, and Kaho'olawe. These gages measure the mass of sediment delivered to the reef in stream water, providing information that forms the beginning of long-term datasets on sediment flux to reefs from steep, volcanic highlands. Scientists are also measuring erosion using networks of permanent markers, or pins, on Moloka 'i, Kaho'olawe, and the island of Guam. These erosion pins are driven into the ground, and periodic measurements are made of the length of pin exposed by soil erosion, especially after heavy rainfalls. These simple measurements complement

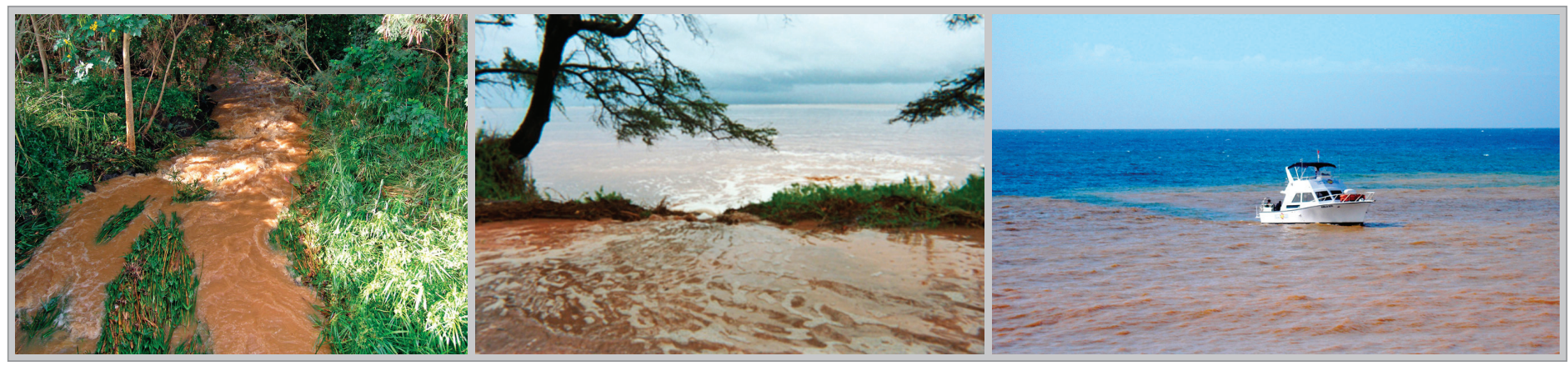

During heavy rains, hillslope and stream-bank erosion provide fine sediment to flood flows (left). At the coast, flood flows enter the nearshore marine environment (center). Sediment-laden freshwater is less dense than seawater, so plumes of muddy water containing sediment from uplands may last for days in the nearshore environment (right), blocking much-needed sunlight that corals use for photosynthesis. These plumes eventually deposit their sediment on the seafloor, smothering corals and preventing them from feeding and reproducing. (USGS photos left/right by Mike Field; middle photo courtesy of Lyndon Dela Cruz.) 


\section{Origins of Ridge to Reef-Connecting Polynesian Tradition to the Present}

The "ridge-to-reef" concept is rooted in the traditions of many Pacific island cultures. Ancient chiefs divided islands into parcels of land running from the mountains to the sea. A landowner, household, or village received a parcel with a supposedly equal share of available environmental resources-a system that is still in use in many Pacific island nations today.

In Hawai'i, these traditional land divisions are called ahupua'a. Ahupua'a boundaries typically form a watershed, running from ridgeline to ridgeline across a valley and from the uplands to the sea. Ideally, each provides access to resources, including wood from forested areas, water from streams, land for cultivating, and fishing from the nearshore coral reef. As shown in this painting, stream water is diverted to narrow taro fields in the upper valley, and broader taro fields fill the wider valley mouth. Coconut trees offer additional food and drink for the village. A coastal fishpond and the nearshore coral reef further provide resources from the sea. (Painting by Marilyn Kahalewai, used with permission from Kamehameha Schools.)

Recent watershed changes on remote Pacific islands are a legacy of human arrival over the past 1,500 years. These alterations have increased dramatically since substantial European contact in the 19th century. Habitats have been transformed by invasive species, wildfire, agriculture, and grazing by feral animals, such as pigs and goats. These changes swept across watersheds, and made their soils dramatically more vulnerable to erosion. Shrinking ground cover and vegetation canopy loss leads to an increase in rainfall intensity on exposed soils and a potential reduction in the binding force of roots. Both effects make soils more vulnerable to erosion. As a result, sediment, nutrients, and other contaminants are now delivered at increased rates to many coral reef ecosystems. By examining the pathways and concentrations of sediment and other contaminants, U.S. Geological Survey scientists are learning how these land-based pollutants imperil coral reef ecosystems.

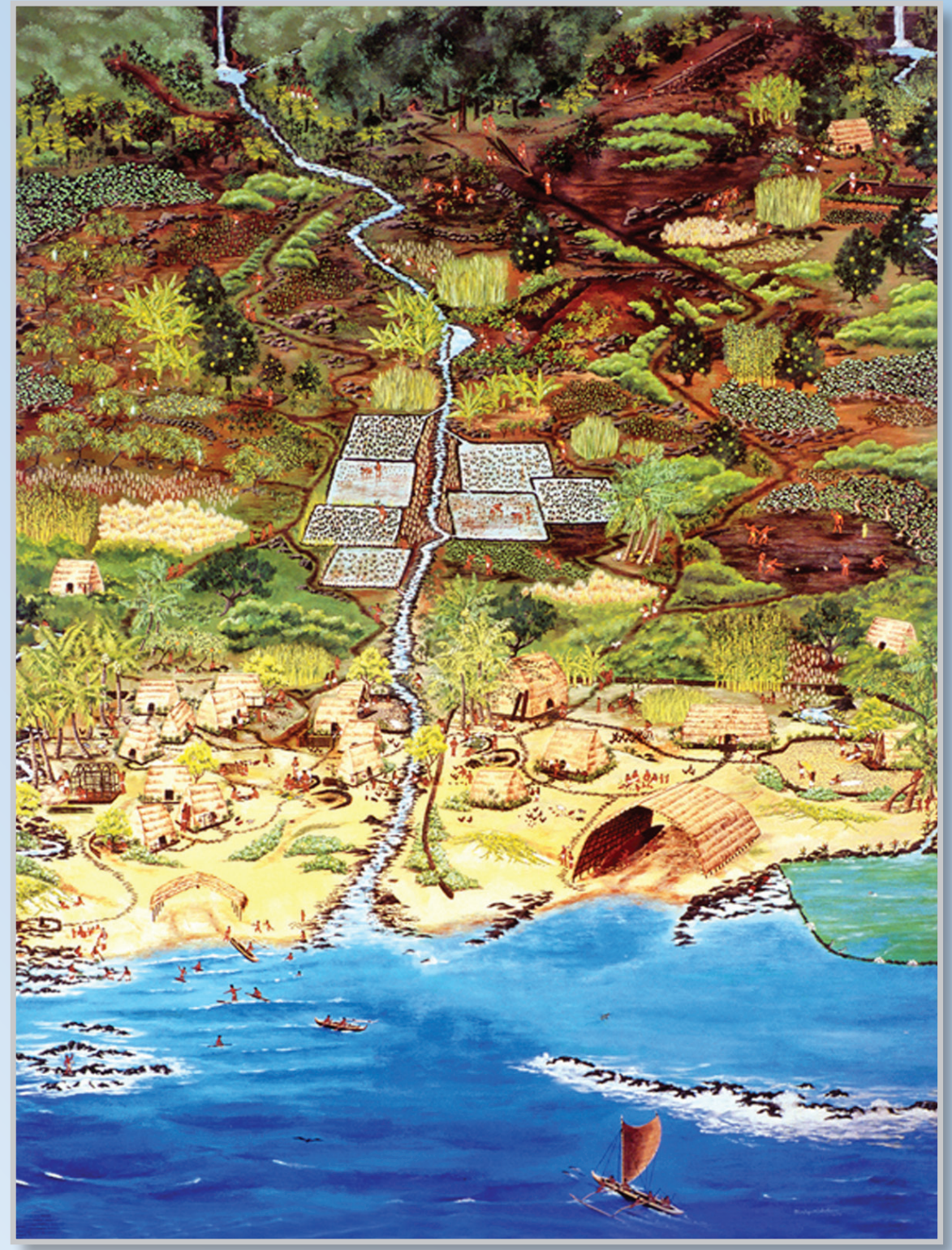

detailed site explorations and can be used by policymakers and local communities to assess the success of mitigation efforts.

\section{Science on the Reef}

On the reef, mud and silt that arrive with floods linger as they are episodically resuspended, degrading the ecosystem. The USGS is using aerial and satellite imagery to map coral distribution and density on reefs. In addition, scientists have placed underwater instruments on reefs to measure water clarity, waves, currents, temperature, salinity, and light penetration. Sediment traps and seabed sampling provide the basis for quantifying sediment accumulation rates and suspended-sediment concentrations. Surveys using portable instruments, as well as long-term measurements at fixed locations, provide information about different areas of the reef. This information is used to characterize sediment deposition rates and size distributions, wave energy associated with sediment resuspension, and the rate at which sediment leaves the reef. Laboratory and field studies of coral response to sedimentation and decreased light availability will help set goals for acceptable levels of sedimentation, while also calibrating numerical models of wave and current processes. These models will help forecast the effects of sedimentation on reef health. The models will also be used to begin identifying threshold levels for sediment input and water turbidity (lack of clarity caused by suspended sediment particles) on coral reefs.

\section{A Look to the Future}

Around the globe, coral reefs are now dying at a rate of nearly $1 \%$ every year. Without protection and mitigation, their future is in jeopardy. In addition to reduced global biodiversity, the loss of these ecosystems will affect millions of Pacific Islanders and others who depend directly on coral reefs for food resources, coastal protection, and tourism and other livelihoods. Changing climate conditions are leading to warmer and more acidic ocean waters that can kill corals, but these threats are impossible to manage at local scales. 


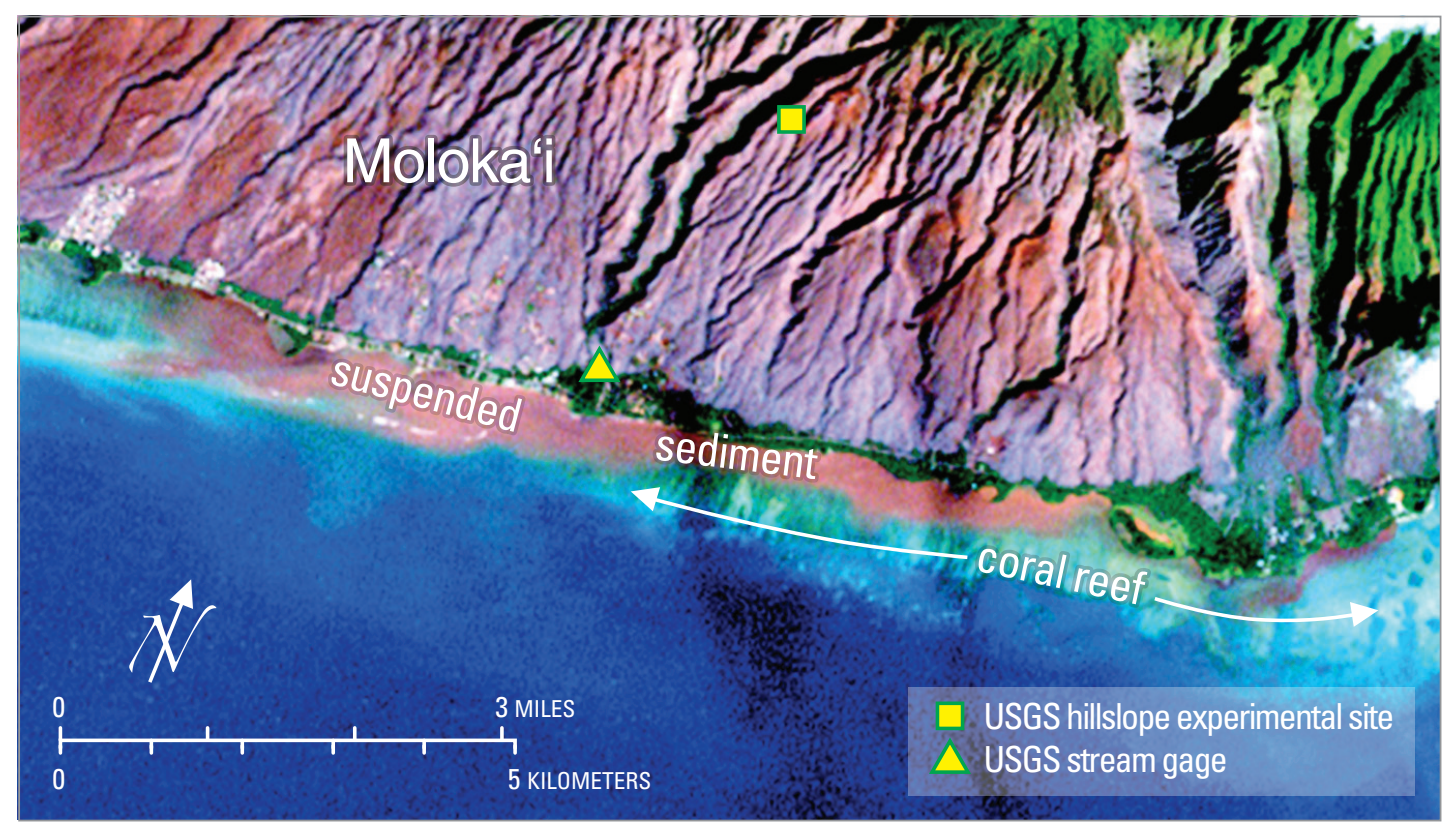

Heavy rains of a Kona storm fell over the Hawaiian island of Moloka'i in November 2001. Water ponding and flowing from eroding hillslopes (see U.S. Geological Survey experimental site) moved mud and silt down through the stream network, past the present site of a USGS stream gage (triangle) and out to the nearshore. Two days later, the suspended sediment was still evident in the water over the reef flat, as seen in this Landsat satellite image. High sediment concentrations in the water column or blanketing the seafloor can harm coral reef ecosystems by reducing light for photosynthesis, impairing coral reproduction, smothering and abrading coral, and increasing the growth of macroalgae.
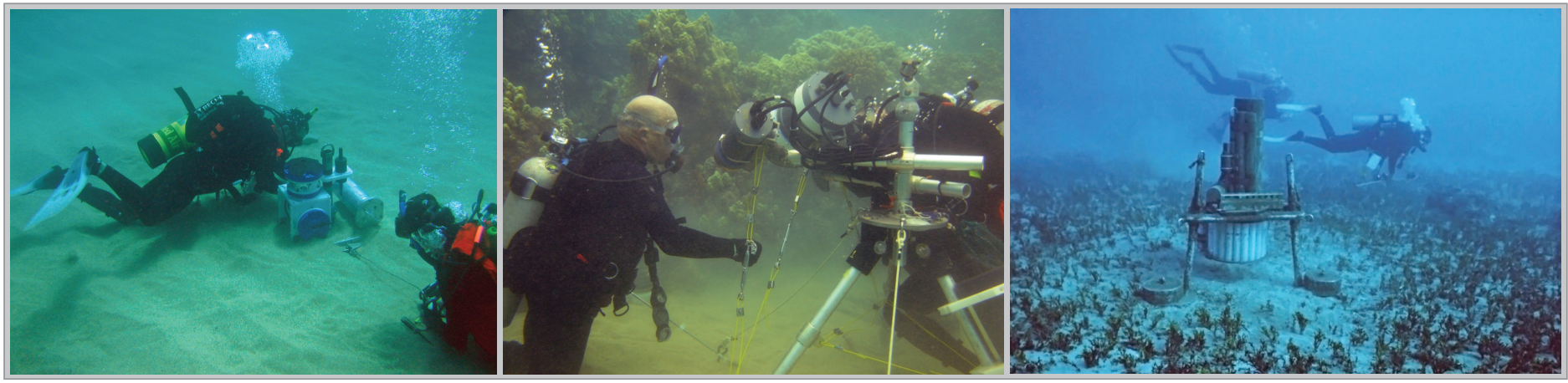

To better understand what happens when sediment from onshore reaches coral reefs, U.S. Geological Survey scientists are using seafloor instruments to measure oceanic conditions. Divers install instruments in a sand channel (left) to measure currents, waves, temperature, and turbidity. An underwater camera system (middle) collects images at specific times throughout each day to document sediment settling on the coral reef. A sediment trap (right) collects suspended sediment as it falls through the water column to the seafloor. The white specimen bottles below the platform are programmed to rotate into place underneath the cylindrical collection funnel for a predetermined number of days. These instruments are being used to help quantify the transport rate and residence time of harmful sediment on the reef. (USGS photos by Mike Field and Tom Reiss.)

Local management actions, however, can reduce damage to reefs from overfishing, anchor damage, and sediment pollution. For example, where small bare areas of watersheds produce disproportionately high sediment loads, it may be economically effective to mitigate them through revegetation. Forecasting the effects of watershed changes on coral reefs will require knowledge gathered through a combination of scientific disciplines.

In Hawai'i this effort involves many partners, including Federal agencies (such as National Park Service, Fish and Wildlife Service, and Environmental Protection Agency), State agencies (such as Department of Health and Department of Land and Natural Resources), other organizations (such as The Nature Conservancy and Hanalei Watershed Hui), and local communities.

Results from ongoing USGS studies will provide partners with crucial scientific information needed to assist coastal resource managers in prioritizing decisions for sound ridgeto-reef management. This information can also be used to guide approaches such as adaptive management and to help understand how ecosystems will respond to changes in climate in Hawai 'i, U.S. Pacific islands, and on high islands elsewhere in tropical seas.
Jonathan D. Stock, Susan A. Cochran, Michael E. Field, James D. Jacobi, and Gordon Tribble

Edited by James W. Hendley II

Graphics and layout by Jeanne S. DiLeo and David R. Jones

For more information contact:

U.S. Geological Survey

400 Natural Bridges Drive

Santa Cruz, CA 95060

(831) $427-4745$

http://coralreefs.wr.usgs.gov/

See also:

The Coral Reef of South Moloka 'i, Hawai ' $i$; Portrait of a Sediment-Threatened Fringing Reef, U.S. Geological Scientific

Investigations Report 2007-5101 (http://pubs.usgs.gov/ sir/2007/5101/)

and

U.S. Coral Reefs-Imperiled National Treasures, USGS Fact

Sheet 025-02 (http:// pubs.usgs.gov/fs/2002/fs025-02/)

This Fact Sheet and any updates to it are available online at http://pubs.usgs.gov/fs/2011/3049/ 